\title{
Porous III-V compound semiconductors: formation, properties, and comparison to silicon
}

\author{
H. FölI ${ }^{*}$, , J. Carstensen ${ }^{1}$, S. Langa ${ }^{1,2}$, M. Christophersen ${ }^{1}$, and I. M. Tiginyanu ${ }^{2}$ \\ ${ }^{1}$ Materials Science, Faculty of Engineering, University of Kiel, Kaiserstr. 2, 24143 Kiel, Germany \\ 2 Technical University of Moldova, Chisinau, Moldova
}

Received 11 March 2003, accepted 30 November 2002

Published online 29 April 2003

PACS 61.43.Gt, 78.60.Hk, 81.05.Rm

Pore formation in n-type III-V semiconductors will be discussed and compared to pore formation in silicon. While by now many different kinds of pores were produced in silicon, the "pore zoology" in III-Vs was rather limited until recently. This paper will briefly review the specific pore morphologies in some compound semiconductors, nucleation and formation mechanisms, the relation to comparable Si pores (including some new observation in $\mathrm{Si}$ ), and the particularly striking features that pores in IIIsemiconductors exhibit many features of self organization and on occasion peculiar luminescence properties.

1 Introduction Electrochemically etched pores in Si have received considerable interest since the discovery of macropores in 1990 [1] and the unexpected optical properties of micropores [2, 3] in 1991. While many questions are still open and new pore types are discovered all the time (see, e.g. $[4,5]$ ), a large body of knowledge exists and can be used as a beacon for pore research in other semiconductors. In recent years, III-V compound semiconductors (essentially GaAs, GaP and InP) have been rendered porous, too [6-11] and while the available data are few and limited, it is nevertheless worthwhile to compare some salient features of pore formation in III-V compounds and Si.

2 General pore formation and geometry While all three basic geometries or size ranges of pores ("micro", "meso", and "macro") have been observed in p- and n-doped Si, in III-V material so far essentially only macropores were found in $\mathrm{n}$ - and particularly $\mathrm{n}^{+}$-type material. If this observation reflects a general property, or simply a lack of experiments, is not clear at present (Recall that macropores in p-type Si were not expected either and discovered much later than those in n-type Si [12-14].). Table 1 gives a comparison of some salient features; indirectly including the work cited in [15-18].

The holes necessary for dissolution seem to be always supplied by avalanche breakdown in the space charge region (SCR). Since all III-V semiconductors contain dislocations and other defects, avalanche breakdown at defects occurs at a much smaller field strength than in (defect-free) $\mathrm{Si}$, causing "soft" reverse $I(V)$ characteristics and leading to preferred pore nucleation at defect sites [19].

While avalanche breakdown as the carrier generating mechanism is a sufficient (but not necessary) reason for pore formation, it will become clear in this paper that it cannot account by itself for the richness of pore geometries and morphologies found so far in III-V compounds. Note that the ubiquitous back side illumination (bsi) used to produce "perfect" macropores in n-type Si is useless in III-V semi-

\footnotetext{
* Corresponding author: e-mail: hf@tf.uni-kiel.de, Phone: + 49431 880-6175, Fax: -6178
} 
Table 1 Some salient features of pore formation.

\begin{tabular}{|c|c|c|c|c|c|c|c|}
\hline \multirow{2}{*}{$\begin{array}{l}\text { material } \\
\text { doping }\end{array}$} & \multicolumn{4}{|l|}{$\mathrm{Si}$} & \multirow{2}{*}{$\begin{array}{l}\text { GaAs } \\
n, n^{+}\end{array}$} & \multirow{2}{*}{$\begin{array}{l}\mathrm{GaP} \\
\mathrm{n}, \mathrm{n}^{+}\end{array}$} & \multirow{2}{*}{$\begin{array}{l}\text { InP } \\
\mathrm{n}, \mathrm{n}^{+}\end{array}$} \\
\hline & $\mathrm{n}$ & $\mathrm{p}$ & $\mathrm{n}^{+}$ & $\mathrm{p}^{+}$ & & & \\
\hline $\begin{array}{l}\text { pore } \\
\text { geometry }\end{array}$ & $\begin{array}{l}\text { micro } \\
\text { meso } \\
\text { macro }\end{array}$ & $\begin{array}{l}\text { micro } \\
\text { meso } \\
\text { macro }\end{array}$ & $\begin{array}{l}\text { meso } \\
\text { macro }\end{array}$ & meso & $\begin{array}{l}\text { meso } \\
\text { macro }\end{array}$ & $\begin{array}{l}\text { meso } \\
\text { macro }\end{array}$ & $\begin{array}{l}\text { meso } \\
\text { macro }\end{array}$ \\
\hline $\begin{array}{l}\text { hole } \\
\text { supply }\end{array}$ & $\begin{array}{l}\text { bsi } \\
\text { fsi } \\
\text { avalanche }\end{array}$ & doping & avalan. & doping & $\begin{array}{l}\text { avalan. } \\
\text { no definite } \\
\text { illumination }\end{array}$ & $\begin{array}{l}\text { avalan. } \\
\text { ffects of fron }\end{array}$ & $\begin{array}{l}\text { avalan. } \\
\text { ide }\end{array}$ \\
\hline $\begin{array}{l}\text { growth } \\
\text { direction } \\
\text { (macro/meso) }\end{array}$ & $\begin{array}{l}100 \\
113 \\
\text { fractal }\end{array}$ & $\begin{array}{l}100 \\
113\end{array}$ & $\begin{array}{l}100 \\
113\end{array}$ & $\begin{array}{l}100 \\
113\end{array}$ & 111B & $\begin{array}{l}111 \mathrm{~B} \\
\text { random }\end{array}$ & $\begin{array}{l}111 \mathrm{~B} \\
\text { current line }\end{array}$ \\
\hline $\begin{array}{l}\text { stopping } \\
\text { planes }\end{array}$ & $\begin{array}{l}111 \\
\text { chains of o }\end{array}$ & $\begin{array}{l}111 \\
\text { tahedrons }\end{array}$ & $\begin{array}{l}111 \\
?\end{array}$ & $\begin{array}{l}111 \\
?\end{array}$ & $\begin{array}{l}111 \mathrm{~A} \\
112 \\
\text { chains of tet }\end{array}$ & $\begin{array}{l}111 \mathrm{~A} \\
112 \\
\text { ahedrons }\end{array}$ & $\begin{array}{l}111 \mathrm{~A} \\
112\end{array}$ \\
\hline luminescence & micro & micro & & & & $\begin{array}{l}\text { macro } \\
\text { meso }\end{array}$ & \\
\hline $\begin{array}{l}\text { oscillations } \\
z=\text { depth along } \\
\text { pore }\end{array}$ & $\begin{array}{l}I(x, y) \\
I(z) \\
I(t) \\
U(t)\end{array}$ & $\begin{array}{l}I(x, y) \\
I(t) \\
U(t)\end{array}$ & $\begin{array}{l}I(x, y) \\
I(t) \\
U(t)\end{array}$ & $\begin{array}{l}I(x, y) \\
I(t) \\
U(t)\end{array}$ & $\begin{array}{l}I(x, y) \\
I(z)\end{array}$ & $\begin{array}{l}I(x, y) \\
I(z)+U(t)\end{array}$ & $\begin{array}{l}I(x, y) \\
I(z)+U(t)\end{array}$ \\
\hline $\begin{array}{l}\text { correlations } \\
\text { between pores }\end{array}$ & S.D.O & S.D.O & & & $(x, y) \mathrm{OD}$ & $\begin{array}{l}\text { S.D.O } \\
z \text { OD }\end{array}$ & $\begin{array}{l}\text { S.D.O } \\
z \text { OD } \\
\text { pore crystal }\end{array}$ \\
\hline
\end{tabular}

Abbreviations and explanations: bsi/fsi = backside or frontside illumination; $(111 \mathrm{~A} / \mathrm{B}$ \} refers to the polarity of the $\{111\}$ planes; $\mathrm{A}=\mathrm{Ga}$ or In layer, $\mathrm{B}=\mathrm{P}$ or As layer; S.D.O = synchronized diameter oscillations; OD = ordered domains. "Stopping planes" means the crystallographic planes often (but not always) encountered as pore walls. Luminescence refers to above background intensity. $I(x, y)$ or $I(z)$ in "Oscillations" means that the current oscillates in space, i.e. that pores are formed, or in depth, respectively, implying pore diameter oscillations, too. $I(t)$ and $U(t)$ denote oscillations in time observed without direct linkage to pore formation, e.g. during electropolishing.

conductors since the minority carrier diffusion length is far smaller than the sample thickness, and that front side illumination experiments so far did not produce many results either.

3 Nucleation of pores The first macropores in Si were obtained by providing lithographically defined points for (extrinsic) nucleation by simply etching tetrahedra into the Si through an oxide mask [15]. This worked very well and has been used to generate macropore arrays with extremely well defined geometries, cf., e.g. [20, 21]. In fact, extrinsic nucleation in Si works unreasonably well, meaning that the macropores follow only the nuclei provided even if the geometry of the nuclei is quite different from the intrinsic geometry the pores would assume otherwise.

But unassisted (intrinsic) nucleation of rather homogeneous pore distributions in Si is not a big problem either. While a micro/mesoporous nucleation layer of about $1 \mu \mathrm{m}$ in thickness may be needed before stable macropore growth commences [22], the pore array is generally quite homogeneous, even though surface defects (like scratches or contamination) may have some influence [23].

In III-V compounds the situation is completely different. Without special techniques, intrinsic nucleation tends to produce very inhomogeneous pore arrays - in the extreme the sample will have one big hole somewhere and not many pores anywhere else. This can be understood in principle by assuming that 

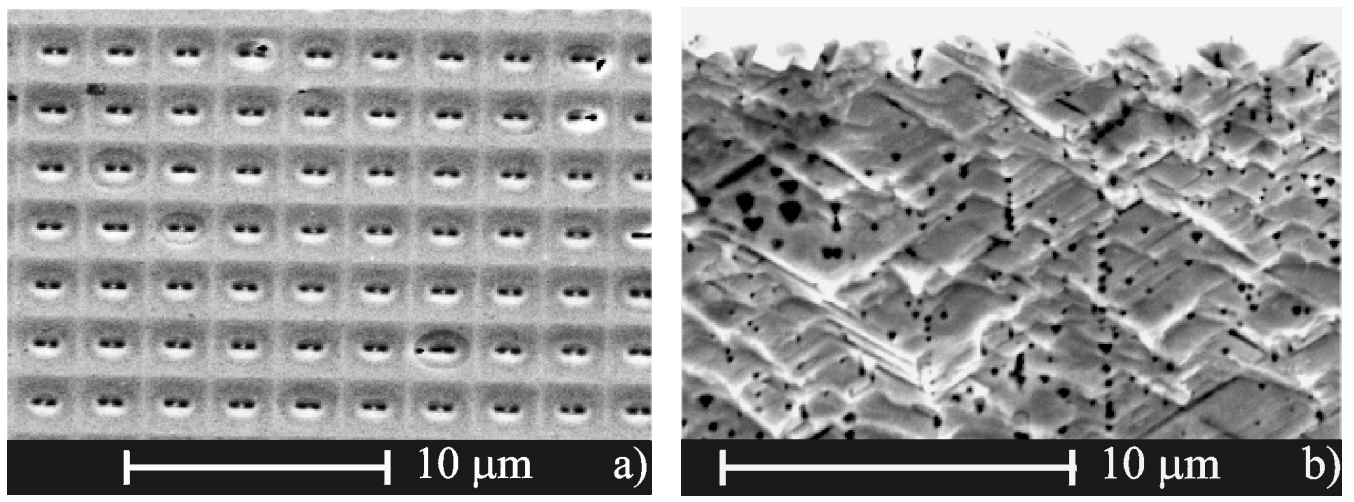

Fig. 1 Lithographically defined pores in GaAs. a) top view; it can be seen that two pores start to grow for every nuclei provided. b) Cross section; showing partial loss of pattern due to parasitic pores.

avalanche breakdown starts at the weakest point where subsequently most of the current will be drawn. It is interesting to discuss why this does not happen in $\mathrm{Si}$. As shown, e.g., in [18], pore formation in $\mathrm{Si}$ due to avalanche breakdown is often (but not always) rather homogeneous although highly inhomogeneous nucleation could be expected, too. Suffice it to mention that in the opinion of the authors (as expressed in the "current burst model" of pore formation [24]), an "avalanche" of carriers will always be terminated after a short time, as well it must if the sample is not to explode, and nucleation of new avalanches thus is going on all the time. The decisive feature then is to which extent "aging" of the exposed surface (by hydrogen passivation in $\mathrm{Si}$ and by other mechanisms in III-V semiconductors) influences the nucleation of new current bursts or avalanche breakdowns.

Several methods were employed to circumvent the nucleation problem, e.g. ion implantation, [25, 26], front side illumination [27], or two-step anodization [28]. Results were mixed; while ion-implantation works, it severely restricts practical work. In the present work, good results have been obtained by optimizing the electrolytic cell and the start-up of the anodization process.

Generating lithographically produced nucleation sites on III-V compounds is possible, of course, but not quite as easy as on $\mathrm{Si}$ (and much more expensive and harder to obtain); thus only one attempt has been reported [29] for (111) InP. The triangular pores obtained were probably "crystallographically oriented" (see below) and followed to some extent the predefined pattern, but a well defined structure was seemingly not obtained.

This paper reports the first attempt to produce ordered pore arrays in (100)GaAs by lithographic prepatterning. Macropores did form, indeed, at most (but not all) of the nuclei provided, the top view of the pore array looks encouraging (Fig. 1a). However, "parasitic" pores started to grow from random sites, too, and all pores immediately branched into the two available $\langle 111 \mathrm{~B}\rangle$ directions. The " $\mathrm{B}$ " refers to the inequality of $\langle 111\rangle$ directions in III-V crystals and designates the direction running from the $\mathrm{P}$ layer to the In layer via one straight bond (the $\langle 111 \mathrm{~A}\rangle$ direction then designating the direction with 3 equivalent bonds), effectively destroying the ordered pore array deeper in the sample (Fig. 1b). Based on this and other observations, it appears that generating regular pore arrays in III-V semiconductors by predefined nucleation is possible, but will be more difficult than in Si.

4 Anisotropy of pore growth So far, micropores in Si seem to be the only kind of pores that are randomly distributed without any relation to the underlying symmetries of the Si lattice. All other pores show preferred growth directions which in Si are always $\langle 100\rangle$ and $\langle 113\rangle$. In some instances this anisotropy is not easily visible, because pores are a mixture of branches in several of the available directions, but in other instances the anisotropy is very well defined. Fig. 2a shows an example for a new kind of Si macropores obtained in n-type Si with organic electrolytes (org) and front-side illumination (fsi) with clearly expressed $\langle 100\rangle$ growth directions for the main pores and the side pores. (It may be noted in 

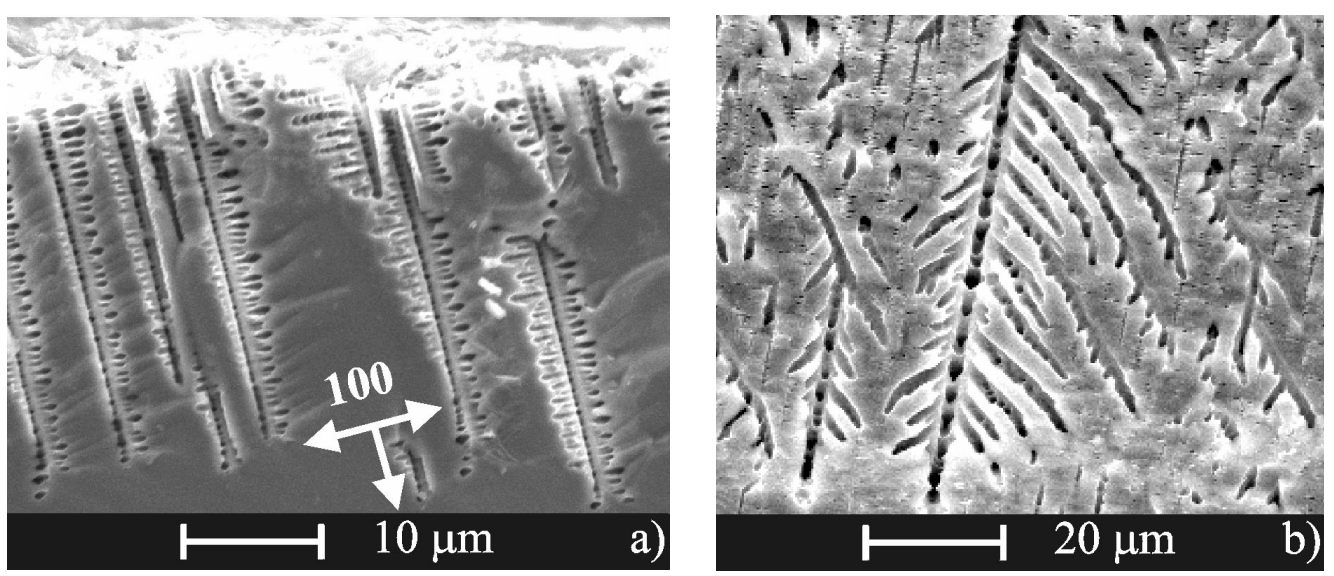

Fig. 2 Examples of anisotropic macropore growth in $\mathrm{Si}$; for details see text.

passing that these "n-macropores (org/fsi)" are a severe challenge to all pore formation models except the current burst model which predicted them.) An example of " $n$-macropores (org/bsi)" including both directions is shown in Fig. $2 b$.

In the III-V-crystals investigated so far, the situation is totally different. Pores either grow in $\langle 111\rangle$ directions (however not in all [30, 31], but only in $\langle 111 \mathrm{~B}\rangle$ directions), or along the "current lines" [32], i.e. more or less perpendicular to the surface - except at the edges of the sample (Fig. 3, 4, and 7 show ex-amples of this). In consequence, the $\{111 \mathrm{~A}\}$ plane acts as efficient "stopping planes" for pore growth.
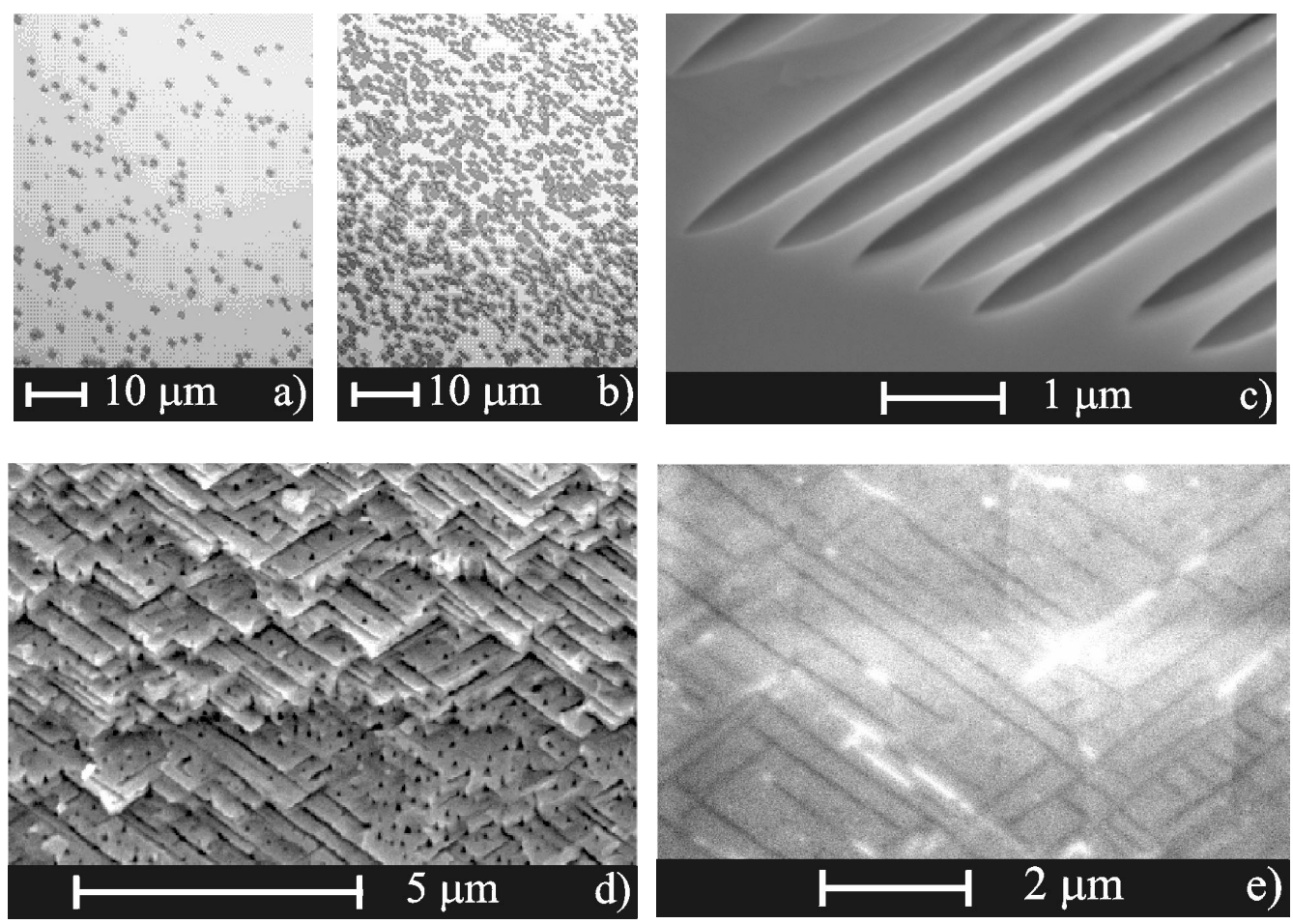

Fig. 3 Examples of crystallographic pores in III-V compounds. a) and b) show the uniformity of the pore nucleation achieved and a direct comparison of the widely different densities obtainable. c) Well developed macropores in GaAs. d) and e) Typical macropores in $\mathrm{InP}$ and $\mathrm{GaP}$, respectively. 


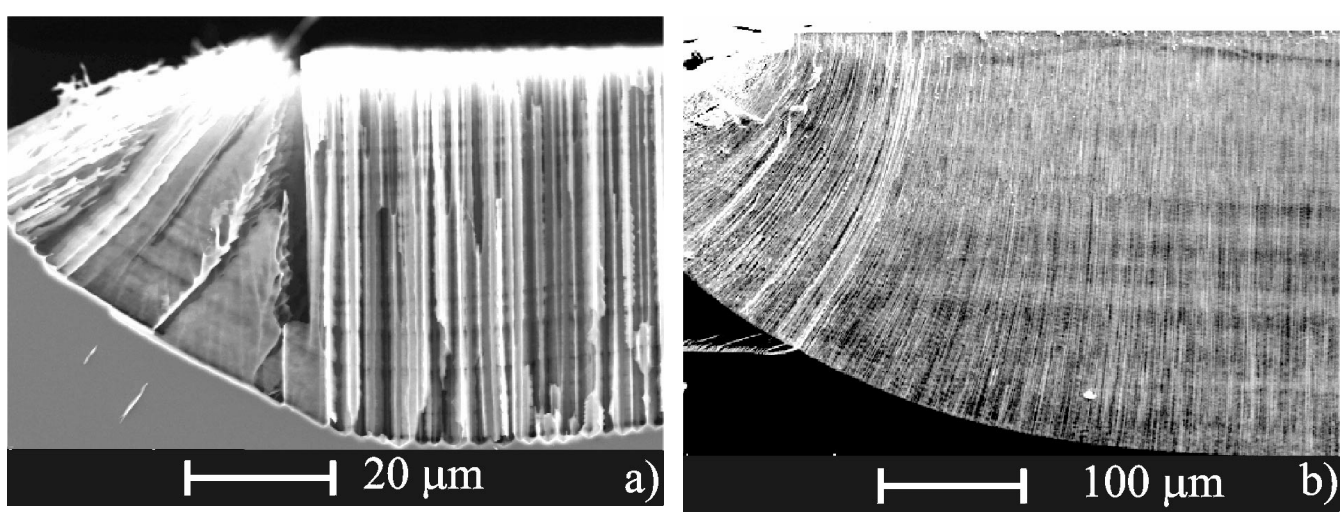

Fig. 4 a) Pores in Si and b) in InP at the edge of the anodized area. The "current line orientation" in InP vs. the "crystallographic orientation" in Si is clearly visible. The dark bands visible in both materials are due to synchronized diameter oscillations.

Accordingly, pores will be classified as being "crystallographically oriented" or "current line oriented" The latter kind has never been observed in Si, Fig. 4 shows a direct comparison. Considering the polar nature of III-V semiconductors, these effects can be understood in principle if basic crystallographic restrictions are combined with the aging concept inherent in the current burst model (for a more detailed consideration see [5]).

5 Self-organization and critical phenomena during pore growth The first general instance of selforganization to be discussed, occurring in Si and all III-V semiconductors investigated so far, are the oscillations of the current in time and/or space, of the voltage in time only, and the pore diameter in space and thus necessarily in time, too; Table 1 gives an overview.

While it is trivial that macro- and mesopores imply by definition oscillations of the current in space, this is not yet widely appreciated. The term "oscillation" here (and similarly in the remainder of the paper) refers to stochastic oscillations, and only implies that e.g. the current $I(x, y)$ varies appreciably with some average spatial frequency in $x$ and $y$. In other words, the experimental fact that randomly nucleated pores in all semiconductors always exhibit a well-defined average pore size and pore distance (and thus rather narrow peaks in reciprocal space), must be seen as a first instance of self-organization expressed as a current oscillation in two-dimensional space.

That the current through one pore may oscillate as a function of depth $z$ (and then necessarily also in time), is evident from the diameter oscillations (including periodic branching already visible in Fig. 2) of single pores occurring in GaAs and Si under certain conditions; Fig. 5 shows some examples. Note that the current/diameter oscillations, while occurring in every pore, are not correlated between the pores, i.e. the (average) phases between the oscillations are random, and the external current (at potentiostatic conditions) thus averages to a fairly constant value.

More recently, voltage oscillations (naturally only observable under galvanostatic conditions) have been observed in InP [33] and GaP [34]. These oscillations do not only occur during pore formation (in contrast to $\mathrm{Si}$, where voltage oscillations so far have only been observed in the electropolishing regime [35-37], but not yet in conjunction with pore formation), but are always (and, as we shall see, by necessity) coupled to synchronized diameter oscillations of the pores; cf. Fig. 6. A detailed discussion of the underlying mechanisms (as far as they are known) can be found in [38].

It is important to note that there are fundamental, if trivial, differences between current and voltage oscillations. While the current flowing through any surface increment at $(x, y)$ at any given time $t$ can have any value whatsoever $\left(\right.$ leading to a total current $\left.I(t)=\sum_{x, y} I(x, y, t)\right)$, the voltage, as an intensive variable, must always be the same at every point of the surface (not counting ohmic losses or other ef- 

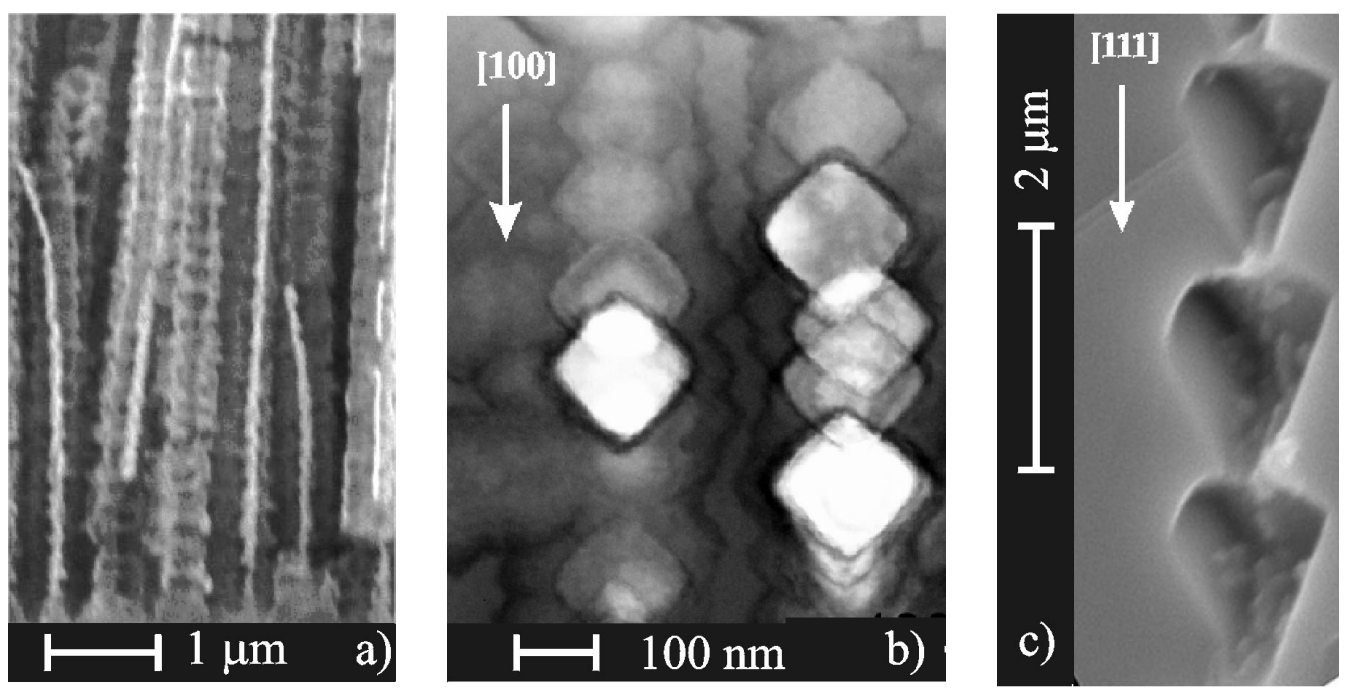

Fig. 5 Diameter oscillations in a) the smallest lithographically defined macropores obtained so far in p-type $\mathrm{Si}$ (using an optimized organic electrolyte), mesopores in Si and macropores in GaAs.

fects possibly inducing lateral currents in the electrolyte, of course). Voltage oscillations then can only occur if a large area of the sample is "synchronized", i.e. if all the pores follow the same dynamic pattern of growth. It is shown in [33] that voltage oscillations then are required to suppress the current oscillations inherently present during pore growth. In short: If the current flowing through a pore inherently
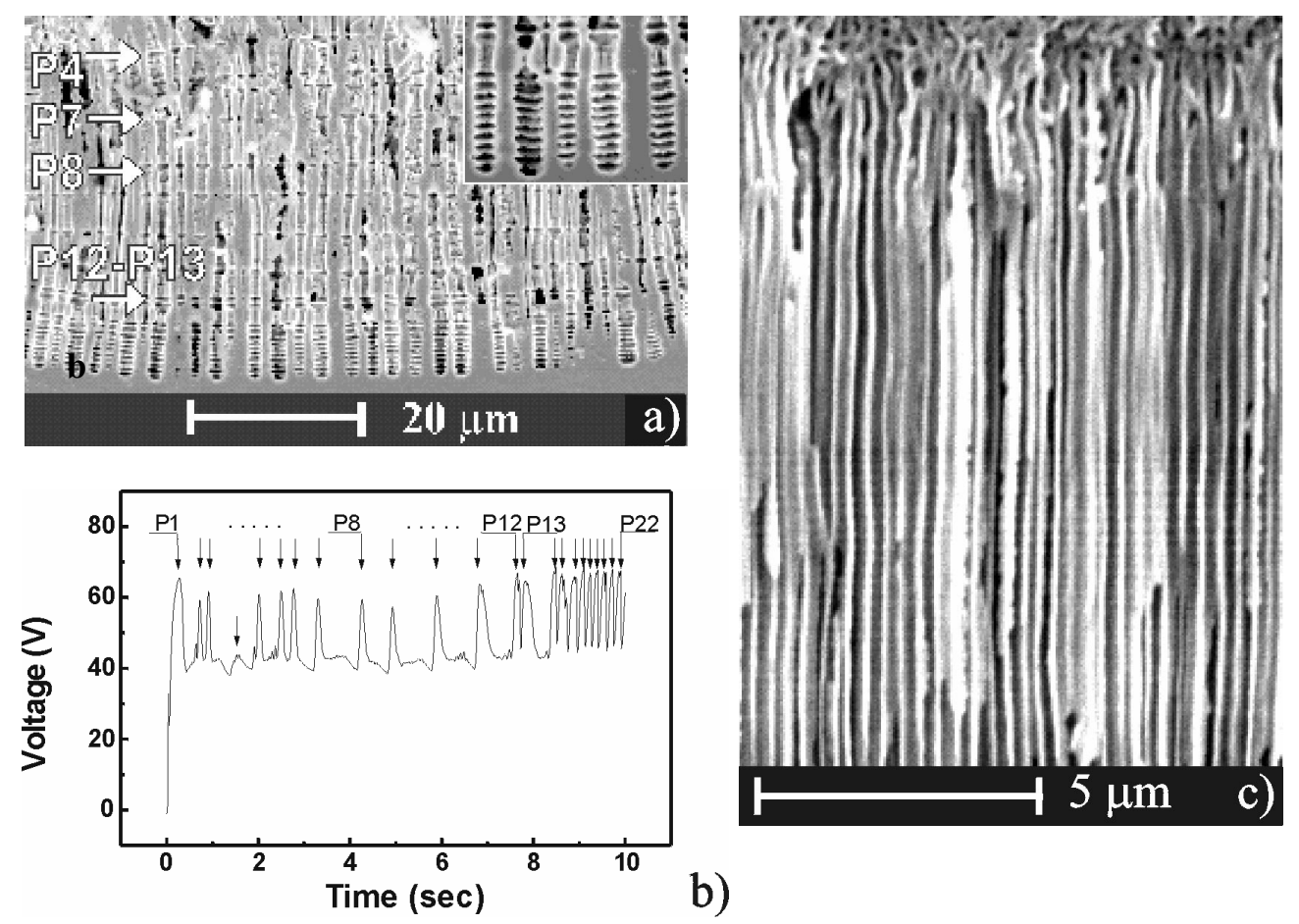

Fig. 6 Synchronized diameter oscillations in InP. a) Diameter oscillations seen under galvanostatic conditions with concurrently occurring voltage oscillations as shown in b). c) Self-induced synchronized diameter oscillations under galvanostatic conditions in a pore crystal. 


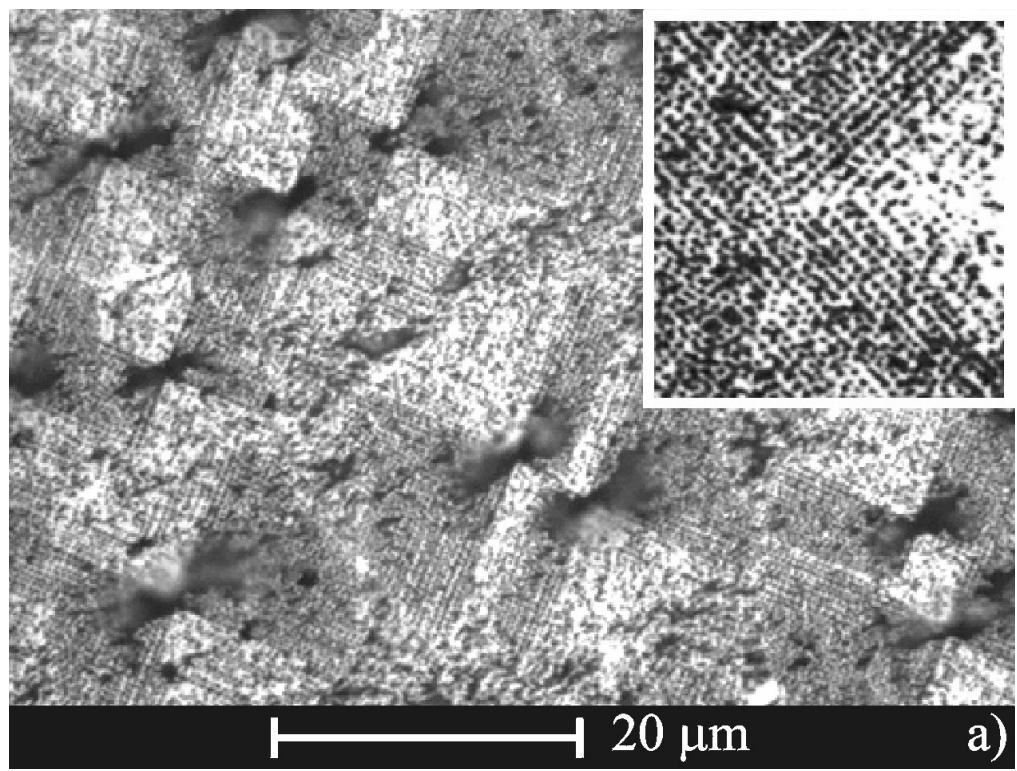

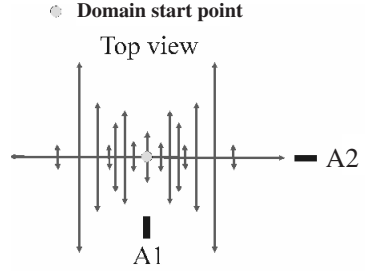

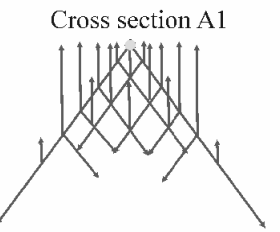

Cross section A2

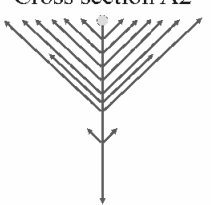

Fig. 7 a) Domains of pores in GaAs with correlations in $(x, y)$ (i.e on the surface). b) Schematic model of domain formation relying on pore retro-growth (i.e. towards the surface).

oscillates (not only required by the current burst model, but also possible, e.g., by assuming that avalanche breakdown at the pore tip occurs in an "on - off" fashion, i.e. in an oscillating manner), the external current (and thus the voltage, too) would still be constant on average as long as the phases of the many pore-oscillators are random. If, however, most if not all pores synchronize their current oscillations and thus forms a domain where morphological features of pores are correlated (as now observed in InP, $\mathrm{GaP}$ and $\mathrm{Si}$ ), the only way to maintain a constant external current is to oscillate the voltage to counterbalance, or better, to suppress the current variations.

In other words: While the current in any individual pore could oscillate without any direct indication of that oscillation in the quantities: external current, external voltage, individual pore morphology, or ensemble morphology, this is not true for voltage oscillations: If the external voltage oscillates, the necessary synchronization is mediated by synchronized diameter oscillations, and there must be at least one large domain of synchronized pore growth. The observation (for the first time) of domains with synchronized diameter oscillations in $\mathrm{Si}$ as demonstrated in Fig. 4b (and in [5]) thus is a strong (but not unambiguous) indication of an inherently oscillating current in Si pores as predicted by the current burst model.

Some more manifestations of correlation between pores are " $(x, y)$-ordered domains" in GaAs (cf. Fig. 7) and the $z$-ordered domains in InP and GaP. In the first case, a unique array of pores as seen on the $(x, y)$ surface is obtained because pores branch off from some primary pores which were nucleated in the center of the square shaped domains and actually grow upwards towards the surface in a manner indicated in Fig. $7 \mathrm{~b}$. The $z$-ordered domains contain pores with synchronized diameter oscillations as already shown for InP in Figs. 4 and 6.

There is, however, a most spectacular additional manifestation of self organization: the formation of two and even three-dimensional single pore crystals in InP under certain conditions; Fig. 8 shows an example. The pores in the pore crystal are always "current-line" oriented and formed under potenstiostatic or galvanostatic conditions, cf. [41] for details. In the latter case synchronized pore diameter oscillations may occur, adding periodicity in $z$-direction and thus providing a three dimensional single pore crystal. In contrast to e.g. self organized pore crystals in $\mathrm{Al}_{2} \mathrm{O}_{3}[39,40]$, the InP pore crystals can be single crystals (demonstrated by the Fourier transform inset in Fig. 8) which, to the best of our knowledge, makes them unique. 


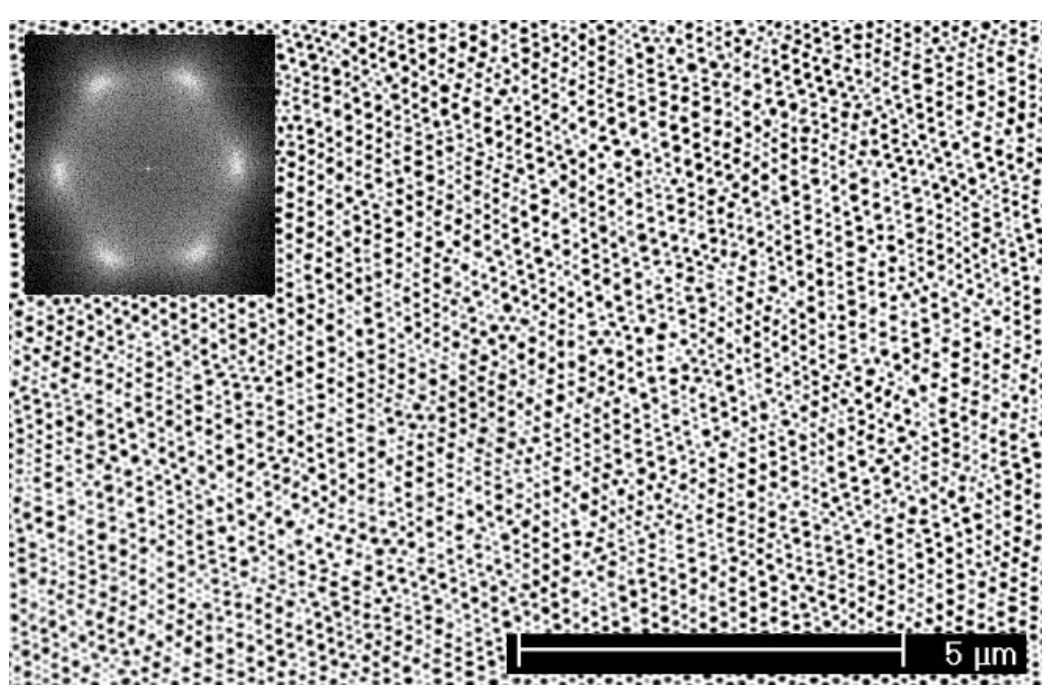

Fig. 8 Macropores in InP arranged in a single crystal (the picture shows only a small part of the total pattern). The inset is a direct Fourier transform of the major part of the picture, proving the single crystallinity (the slight distortion is due to specimen tilt in the SEM).

Pore crystal formation, however, only commences after an induction (or nucleation) period during which a dense array of $\langle 111 \mathrm{~B}\rangle$ oriented pores is formed. While the geometry of this nucleation layer is responsible for the pore crystal formation (see [41] for details), it neatly demonstrates another essential point: The obvious steady-state structure of the pore crystals (with pores that easily penetrate through the whole $600 \mu \mathrm{m}$ sample) can not be reached directly - it always needs a "sorting-out" step, as evidenced by suddenly lowering (or turning off completely) the current for a very short period of time. The results are shown in Fig. 9 where it is demonstrated that at the onset of current line oriented pores is obviously a critical phenomena - the InP sample rather quickly "forgets" about its preferred structure and has to build it up "from scratch" again. This not only supports the aging concept of the current burst model, but unambiguously proofs that avalanche breakdown, while supplying the necessary holes, is not decisive for the pore morphology. As Fig. 9 amply demonstrates, this property of the pore formation process offers
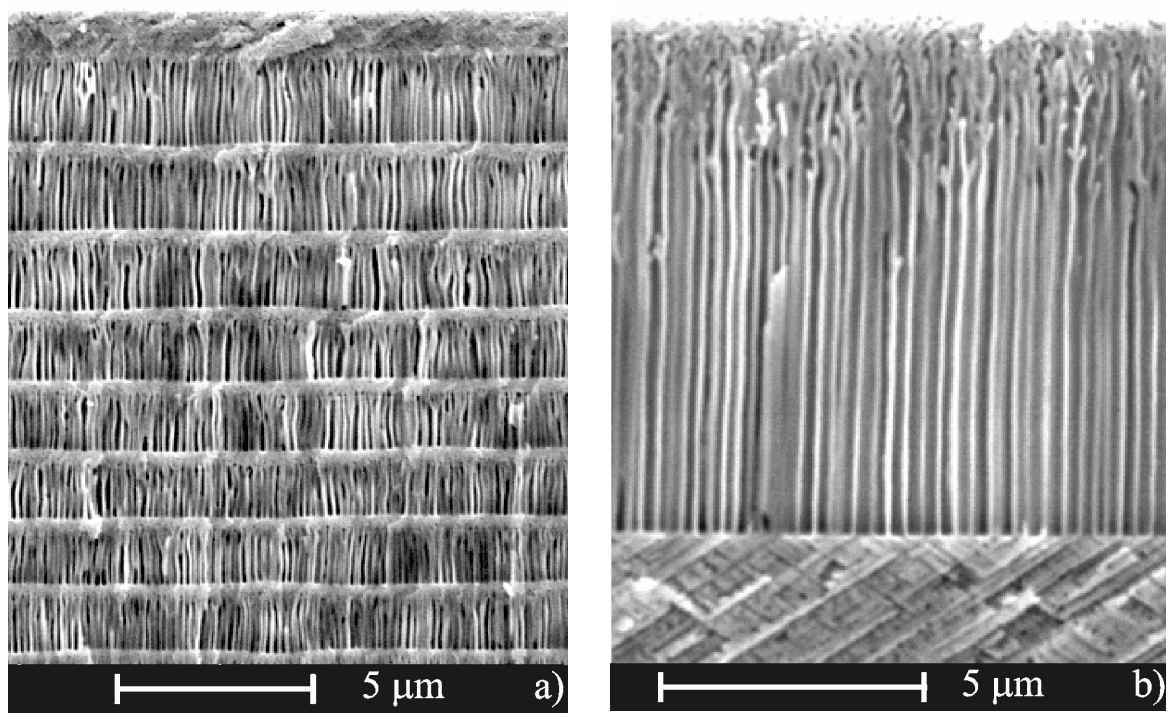

Fig. 9 a) The first three dimensional pore crystal (in InP). The depth modulation was achieved by switching between current line oriented pores and crystallographically oriented pores by suitable current modulations. b) Transition between current line and crystallographic pores in InP. 

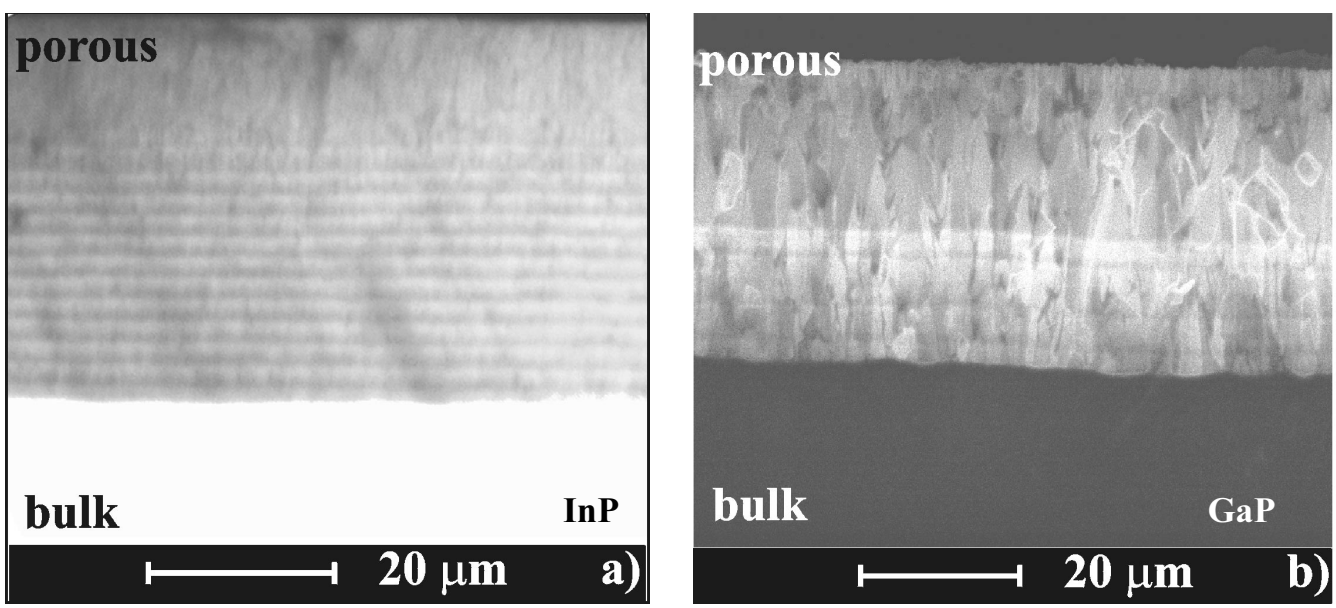

Fig. 10 Direct comparison of the cathodoluminescence from porous layers in a) InP and b) GaP.

rather interesting applications, allowing the formation of three-dimensional structures in the sub- $\mu \mathrm{m}$ region.

6 Luminescence of porous layers Porous III-V compounds show some interesting luminescence properties, cf. [42, 43], which are not fully understood at present. Suffice it to say that (meso)porous InP layers do not show any (cathodo)luminescence when subjected to the electron beam in a SEM, while the light produced from the bulk of the crystal is easily detected (Fig. 10). This is not unexpected, because the large surface area in the porous region may efficiently recombine electron-hole pairs and thus quenches the radiative transitions.

Spectacularly, in $\mathrm{GaP}$ the opposite is true: The porous layer produces an extremely intensive luminescence, not only at the frequency corresponding to the band gap energy, but also at double frequency, i.e. for the second harmonic. Details can be found in [43], this property is of obvious interest for potential applications. The mechanism for this strongly increased luminescence is not fully understood at present, but it should be kept in mind that GaP is an indirect semiconductor and only useful for optoelectronics because strong radiative transitions can be induced via localized excitons introduced by isoelectronic doping. Mechanisms of luminescence thus are much more complicated than in direct semiconductors and the effect of porosity is harder to assess theoretically.

7 Conclusions While pore formation in $\mathrm{Si}, \mathrm{GaAs}, \mathrm{GaP}$, and $\mathrm{InP}$ shows many material specific idiosyncrasies that must be treated in the context of the detailed material properties (including its basic chemistry) a unified framework for understanding pore formation in semiconductors is slowly emerging. It is truly interdisciplinary, combining chemistry, electrochemistry, semiconductor and solid state physics, and stochastic physics in particular.

Acknowledgements The authors are indebted to their colleagues P. Schmuki, J.-N. Chazalviel, J. Kelly, and R. Wehrspohn for support and fruitful discussions. This work was supported by the Deutsche Forschungsgemeinschaft (Förderungsnummer: FO 258/1-2 and 436 MOL 113/2/0-1).

\section{References}

[1] V. Lehmann and H. Föll, J. Electrochem. Soc. 137, 653 (1990).

[2] L. T. Canham, Appl. Phys. Lett. 57, 1046 (1990).

[3] V. Lehmann and U. Gösele, Appl. Phys. Lett. 58, 856 (1991).

[4] C. Jäger, B. Finkenberger, W. Jäger, M. Christophersen, J. Carstensen, and H. Föll, Mat. Sci. Eng. B 69-70, $199(2000)$. 
[5] M. Christophersen, S. Langa, J. Carstensen, I. M. Tiginyanu, and H. Föll, phys. stat. sol. (a) 197, 197 (2003), these proceedings.

[6] E. Kukino, M. Amiotti, T. Takizawa, and S. Arai, Jap. J. Appl. Phys. 34, 177 (1995).

[7] B. H. Erne, D. Vanmaekelbergh, and J. J. Kelly, J. Electrochem. Soc. 143, 305 (1996).

[8] I. M. Tiginyanu, G. Irmer, J. Monecke, A. Vogt, and H. L. Hartnagel Semicond. Sci. \& Technology 12, 491 (1997).

[9] F. M. Ross, G. Oskam, P. C. Searson, J. M. Macaulay, and J. A. Liddle, Philos. Mag. A 75, 525 (1997).

[10] A. Anedda, A. Serpi, V. A. Karavanskii, I. M. Tiginyanu, and V. M. Ichizli, Appl. Phys. Lett. 67, 3316 (1995).

[11] K. Kuriyama, K. Ushiyama, K. Ohbora, Y. Miyamoto, and S. Takeda, Phys. Rev. B 58, 1103 (1998).

[12] E. K. Propst and P. A. Kohl, J. Electrochem. Soc. 141, 1006 (1994).

[13] M. Christophersen, J. Carstensen, A. Feuerhake, and H. Föll, Mater. Sci. Eng. B 69-70, 194 (2000).

[14] K. J. Chao, S. C. Kao, C. M. Yang, M. S. Hseu, and T. G. Tsai, Electrochem. Solid-State Lett. 3, 489 (2000).

[15] R. L. Smith and S. D. Collins, J. Appl. Phys. 71, R1 (1992).

[16] V. Parkhutik, Solid-State Electron. 43, 1121 (1999).

[17] J.-N. Chazalviel, R. B.Wehrspohn, and F. Ozanam, Mater. Sci. Eng. B 69-70, 1 (2000).

[18] V. Lehmann, R. Stengl, and A. Luigart, Mater. Sci. Eng. B 69-70, 11 (2000).

[19] P. Schmuki, J. Fraser, C. M. Vitus, M. J. Graham, and H. S. Isaacs, J. Electrochem. Soc. 143, 3316 (1996).

[20] F. Müller, A. Birner, U. Gösele, V. Lehmann, S. Ottow, and H. Föll, J. Porous Mater. 7, 201 (2000).

[21] U. Grüning, V. Lehmann, S. Ottow, and K. Busch, Appl. Phys. Lett. 68, 747 (1996).

[22] M. Hejjo Al Rifai, M. Christophersen, S. Ottow, J. Carstensen, and H. Föll, J. Electrochem. Soc. 147, 627 (2000).

[23] M. Hejjo Al Rifai, M. Christophersen, S. Ottow, J. Carstensen, and H. Föll, J. Porous Mater. 7, 33 (2000).

[24] J. Carstensen, M. Christophersen, and H. Föll, Mater. Sci. Eng. B 69-70, 23 (2000).

[25] P. Schmuki, L. E. Erikson, D. J. Lockwood, B. F. Mason, J. W. Fraser, G. Champion, and H. J. Labbe, J. Electrochem. Soc. 146, 735-740 (1999).

[26] I. M. Tiginyanu, C. Schwab, J.-J. Grob, B. Prevot, H. L. Hartnagel, A. Vogt, G. Irmer, and J. Monecke, Appl. Phys. Lett. 71, 3829 (1997).

[27] M. M. Carrabba, N. M. Nguyen, and R. D. Rauh, J. Electrochem. Soc. 134, 1855 (1987).

[28] M. Hao, H. Uchida, C. Shao, T. Soga, T. Jimbo, and M. Umeno, J. Crystal Growth 179, 661 (1997).

[29] T. Takizawa, Sh. Arai, and M. Nakahara, Jap. J. Appl. Phys. 54, L643 (1994).

[30] F. M. Ross, G. Oskam, P. C. Searson, J. M. Macaulay, and J. A. Liddle, Philos. Mag. A 75, 525 (1997).

[31] S. Langa, J. Carstensen, M. Christophersen, H. Föll, and I. M. Tiginyanu, Appl. Phys. Lett. 78, 1074, (2001).

[32] S. Langa, I. M. Tiginyanu, J. Carstensen, M. Christophersen, and H. Föll, Electrochem. Solid-State Lett. 3, 514 (2000).

[33] S. Langa, J. Carstensen, I. M. Tiginyanu, M. Christophersen, and H. Föll, Electrochem. Solid-State Lett. 4, G50 (2001).

[34] M. A. Stevens-Kalceff, S. Langa, I. M. Tiginyanu, J. Carstensen, M. Christophersen, and H. Föll, Mat. Res. Soc. Symp. Proc. 638, F5.31.1 (2001).

[35] F. Ozanam, J.-N. Chazalviel, A. Radi, and J. Etman, J. Electrochem. Soc. 139, 2491 (1991).

[36] V. Lehmann, Electrochem. Soc. 143, 1313 (1996).

[37] V. Parkhutik, E. Matveeva, R. Perez, J. Alamo, and D. Beltrán, Mat. Sci. Eng. B 69-70, 553 (2000).

[38] S. Langa, J. Carstensen, M. Christophersen, I. Tiginyanu, and H. Föll, phys. stat. sol. (a) 197, 186 (2003), these proceedings.

[39] O. Jessensky, F. Müller, and U. Gösele, J. Electrochem Soc. 145, 3735 (1998).

[40] O. Jessensky, F. Müller, and U. Gösele, Appl. Phys. Lett. 72, 1173 (1998).

[41] S. Langa, M. Christophersen, J. Carstensen, I. Tiginyanu, and H. Föll, phys. stat. sol. (a) 197, 77 (2003), these proceedings.

[42] P. Schmuki, D. J. Lockwood, H. J. Labbe, and J. W. Fraser, Appl. Phys. Lett. 69, 1620 (1996).

[43] M. A. Stevens-Kalceff, I. M. Tiginyanu, S. Langa, and H. Föll, J. Appl. Phys. 89, 2560 (2001). 